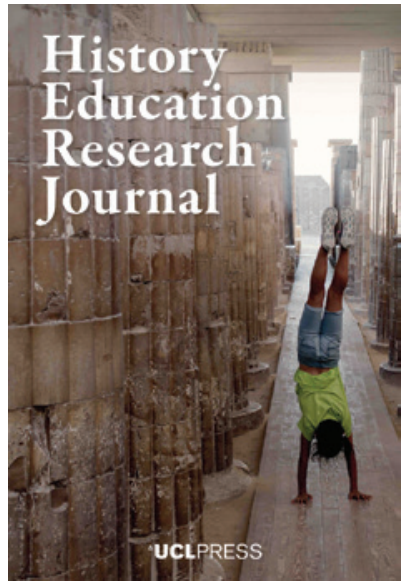

${ }^{\Perp}$ UCLPRESS

HISTORY EDUCATION RESEARCH JOURNAL

ISSN 2631-9713 (Online)

Journal homepage:

https://www.uclpress.co.uk/pages/history-educationresearch-journal

\title{
History teachers' pedagogical reasoning and the dynamics of classroom implementation in Ghana
}

\author{
Gideon Boadu (D, Debra Donnelly (iD and Heather Sharp (D)
}

\section{How to cite this article}

Boadu, G., Donnelly, D. and Sharp, H. (2020) 'History teachers' pedagogical reasoning and the dynamics of classroom implementation in Ghana'. History Education Research Journal, 17 (2), 179-94. Online. https://doi.org/10.14324/HERJ.17.2.04

Submission date: 10 January 2020

Acceptance date: 8 June 2020

Publication date: 20 October 2020

\section{Peer review}

This article has been peer reviewed through the journal's standard double-blind peer review, where both the reviewers and authors are anonymized during review.

\section{Copyright}

(C) 2020 Boadu, Donnelly and Sharp. This is an open-access article distributed under the terms of the Creative Commons Attribution Licence (CC BY) 4.0 https://creativecommons.org/licenses/ by/4.0/, which permits unrestricted use, distribution and reproduction in any medium, provided the original author and source are credited.

\section{Open access}

The History Education Research Journal is a peer-reviewed open-access journal. 


\title{
History teachers' pedagogical reasoning and the dynamics of classroom implementation in Ghana
}

\author{
Gideon Boadu*, Debra Donnelly and Heather Sharp - University of \\ Newcastle, Australia
}

\begin{abstract}
The Ghanaian senior high-school history curriculum encourages teachers to guide students to explore, question and construct historical interpretations, rather than accept established historical narratives. This study investigates how those teachers conceive and implement the curriculum intent by exploring their pedagogical reasoning and classroom practices. The project described in this paper draws from a range of investigative instruments including in-depth interviews, classroom observations, post-lesson interviews and teachers' planning paperwork from 15 public senior high schools in Ghana's Central Region. This research found that teachers' pedagogical reasoning was consistent with constructivist educational theory as well as responsive to the history curriculum, but that their stated understandings did not align with classroom practice. The findings indicate limited constructivist strategies in history lessons, as most teachers were didactic in approach and tended to teach history as a grand narrative.
\end{abstract}

Keywords: pedagogical reasoning; pedagogical practice; history teaching; history curriculum; constructivism

\section{Introduction}

Over the last few decades, there has been a growing acceptance that students should be positioned as the developers of their own knowledge and understanding (see, for example, Power et al., 2019; Sharan, 1990). This conception shifts teaching from teachers as transmitters of knowledge to a student-oriented, constructivist outlook in which students take an active role in their learning. Research suggests that best practice in history teaching involves encouraging students to progress in their search for historical knowledge in order to attain understanding of concepts and acquire useful intellectual and practical dispositions (Wineburg, 2001). To this end, researchers have made repeated calls for history teachers to involve students in activities and processes that allow for active engagement with the discipline (Lee, 2011). Given the crucial roles that history teachers play in interpreting and implementing education policies and curricula, it is important that they possess strong foundational knowledge of pedagogy and translate such understandings into their decisions and activities to encourage students' understanding of history. Hence, teachers' reasoning about their teaching, their decision making and instructional reflections - that is, their pedagogical reasoning, as well as their pedagogical practices - present valuable opportunities for ongoing research. This paper explores how secondary history teachers in Ghana reason about their pedagogy and implement their classroom practices, and evaluates 
the extent to which these resonate with the constructivist-oriented recommendations in Ghanaian history curriculum documents.

\section{Positioning Ghana's senior secondary history curriculum within constructivism}

The educational theory of constructivism regards knowledge as developmental, subjective and internally built, and socially and culturally negotiated (Fosnot, 1996). Constructivist teachers organize content and purposeful learning activities, and provide direction and support to enhance knowledge construction. The theory of constructivism is applicable to a range of school subjects; its relevance to history is well documented (see, for example, Knupfer, 2013). For instance, studies show that small group discussions, classroom debates and brainstorming present students with opportunities to use historical vocabulary and concepts, attain higher levels of reasoning and develop historical empathy (Perrotta, 2018; Van Boxtel and Van Drie, 2009).

In Ghana, history has been a fringe subject over the last three decades following the 1987 educational reforms, which saw history lose its privileged position as a core subject in schools. The current secondary history curriculum, which has been in operation since September 2010, covers a set of chronologically sequenced themes that reflect multiple perspectives on Ghana and Africa from prehistoric times to 1991. The curriculum encourages teachers to aim at enhancing students' understanding of the relevance of their learning. Emphasis is placed on discipline-specific skills such as sourcing, corroboration, and context-based analyses and interpretation of evidence (Ministry of Education, 2010). Teachers are encouraged to guide students to locate, analyse and interpret multiple sources of historical evidence through activities such as projects, role play, class discussion, experiments, investigative study and field trips (ibid.).

Consequently, the training and assessment of history teachers are based on a range of criteria, including source analysis and interpretation, which are aimed at building their self-efficacy to implement constructivist practices in schools.

This paper reports on the following research questions:

(1) How do history teachers reason about their pedagogy?

(2) Do teacher practices align with constructivist principles?

(3) What is the relationship between these teachers' stated pedagogical reasoning and classroom practices?

\section{Conceptual framework}

Debates on the sources and forms of teacher knowledge have raged for a long time, centring on issues such as the nature of knowledge, its mode of acquisition and growth, forms of representation, and the theory-practice divide in educational practice (Barton and Levstik, 2004). Shulman (1987) argues that pedagogical content knowledge is a model of pedagogical reasoning for teaching that embraces a dynamic amalgam of content, procedural and pedagogical dispositions on which teachers' practices must be based. Underlying this model of pedagogical reasoning is the idea that teaching starts with a reason, a process of reasoning, and climaxes in the performance of activities and a rethinking of the process (Shulman, 1987). This means that teachers grasp an idea, probe further to understand the idea, and transform it into a form that is intelligible to students. 
Early application of the pedagogical reasoning and action model to history showed that wise practitioners in history drew knowledge from a range of sources, alternated between different models of teaching, and exhibited a deep understanding of their professional practices (Wineburg and Wilson, 1991). Several other researchers have subsequently sought to delineate frameworks on teacher knowledge and competence in history (see Heuer et al., 2017; Husbands et al., 2003). For instance, Heuer et al.'s (2017) recent Heidelberg Model for Competence in History Teaching emphasizes the importance of the intersection of knowledge and expertise for effective history teaching. Husbands et al. (2003) identify three forms of knowledge bases that are deployed by history teachers: knowledge about history; knowledge about students; and knowledge of practices, resources, and activities that facilitate learning. A common thread in these various approaches to teacher knowledge is that expert practitioners possess strong disciplinary and pedagogical frames with which to transform knowledge and engage students in interesting and meaningful ways.

From the discussions about the sources and models of teacher knowledge, it is argued that effective practice in history involves an interplay of three factors. These are disciplinary reasoning (deep understanding of the subject, its foundations and purposes), pedagogical reasoning (purposeful and reflective mental and physical planning, instructional goals, purposes and decisions) and pedagogical activities (implementation and mediation of activities and tasks in the classroom). While disciplinary reasoning is widely recognized as fundamental to history teaching, this study focuses on teachers' pedagogical reasoning and classroom practice. Findings relating to aspects of participants' disciplinary reasoning have been published elsewhere (see Boadu, 2020). Figure 1 proposes how pedagogical reasoning and classroom practice interact to enhance understanding.

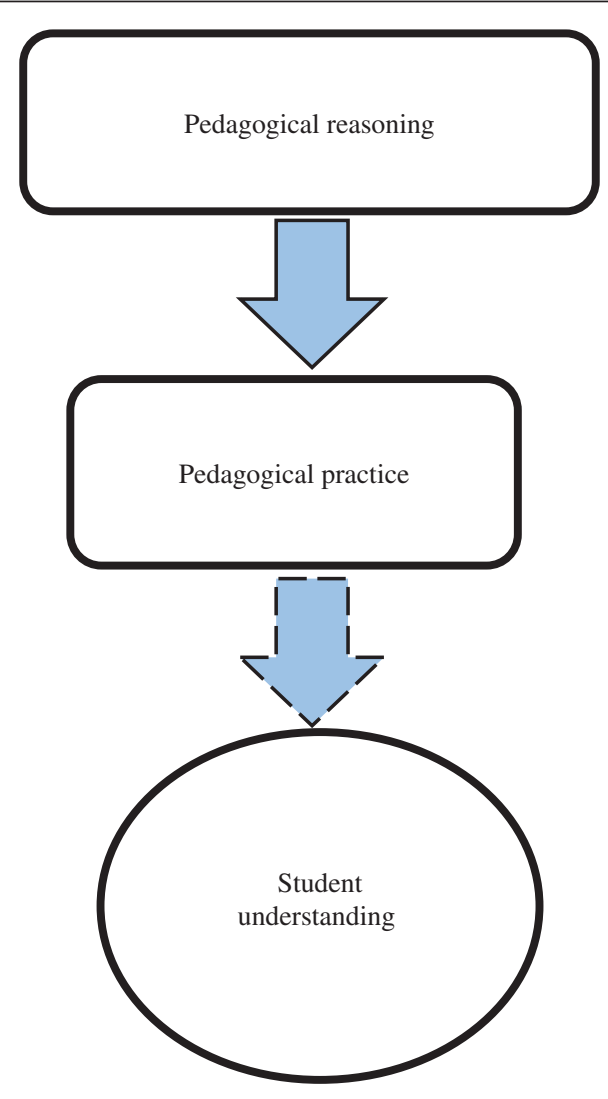

Figure 1: Hypothetical interaction between teacher reasoning and practice 
Pedagogical reasoning is employed in this study to explain how teachers think and rethink their teaching and make important decisions about their lessons. It is conceptualized as the middle ground of the pedagogical process and the centre of the nexus between meaning and practice. The hypothesized relationship, as shown in Figure 1, is that teachers' pedagogical reasoning could influence their pedagogical practice and that pedagogical practice can impact on students' understanding. However, this interaction between reasoning and practice may not be linear, owing to the impact of mediating factors including curriculum structures, context and teacher orientation to pedagogy. Neither can it be argued that the relationship would ensure optimal levels of understanding in all cases. Nevertheless, based on previous research (see, for example, Bennett, 2014), it is assumed that this interaction can result in positive learning experiences and outcomes.

\section{Lesson planning and decision making}

Research shows that expert teachers exhibit the trait of effective and organized planning as it offers the opportunity to analyse how goals and teacher competence are articulated and activated (Farrell, 2013). In history education, planning is argued to be a complex task that requires teachers to balance content and its significance, depth and outline, approaches to enquiry, and learning activities (Byrom and Riley, 2003).

Notwithstanding the importance of lesson planning, strict adherence to highly structured lesson plans could constrain creativity and flexibility to accommodate unplanned and unexpected situations in the classroom (Byrom and Riley, 2003). Research shows that experienced teachers reject strict lesson plan requirements as unproductive, forceful and dishonest; instead, they favour the use of flexible formats (Shaw, 2017). Hence, making room for adjustments in response to classroom realities is an important consideration when planning and implementing lesson plans. Nevertheless, the difference between planned lessons and classroom reality could constrain planning efforts. Studies show that teachers spend less time on physical lesson planning, or give up physical lesson planning at some stage in their careers, because their actual classroom practices often differ from planned activities. However, they hardly approach lessons without some form of mental planning (Farrell, 2002, 2013). Given the unpredictable elements of classroom teaching, it is reasonable to consider lesson plans as records of teacher-student interaction and not a final action plan.

\section{Methods}

\section{Research design}

This paper is drawn from a larger study that employed a hermeneutic phenomenological research design to investigate history teachers' reasoning and implementation of history pedagogy in Ghana. With the same hermeneutic lens, this paper reports on the nuances of teachers' sense-making of their reasoning and practices in history. The hermeneutic basis of this study lies in its focus on teachers' own accounts of their pedagogical experiences in history, and the meanings of such experiences through fusion with the researchers' horizons of interpretation (Gadamer, 2004). The justification for this is that until the meanings of teachers' experiences are coherently revealed through the researchers' interpretative engagement with the data, they could remain hidden in individual teacher expressions and actions (Gadamer, 2004; Van Manen, 1990). The hermeneutic phenomenological approach therefore made it possible to question the underlying elements that constituted teachers' experiences in order to unearth the 
foundations of their pedagogical reality (Van Manen, 1990) and to distinguish between their accounts and classroom technique.

\section{Participants and data sources}

Participants in this study were 24 history teachers drawn from 15 public secondary schools in Ghana's Central Region. Teachers are the primary implementers of the history curriculum, and they have the mandate to teach students to attain skills and dispositions relevant to the discipline of history. Their position at the coalface of history education places them to uniquely influence student learning and understanding.

The participants taught in schools that ranged in context from: single-sex and co-educational settings; religious and secular orientations; and district, municipal and metropolitan locations. For the purpose of this study, schools that were located in the metropolitan and municipal areas were grouped together as urban schools, while schools in the district assemblies were classified as suburban schools. These classifications yielded four dichotomous variations of schools: urban-secular, urbanreligious, suburban-secular and suburban-religious schools. The snowball sampling technique was employed to locate history teachers in the schools offering history, starting off with three initial teachers who were known to teach history. History teachers in each school classification were invited to participate in the study, and their inclusion was dependent on their willingness to be involved in the study. The gender distribution was 16 male teachers and 8 female teachers. All participants had completed a fouryear university degree in education and majored in either history or social studies. In addition to their initial teacher qualification, two participants held postgraduate qualifications.

This study draws data from in-depth semi-structured interviews, lesson observations, post-observational interviews, and teachers' lesson plans and schemes of work. Interviewing, observing and analysing documents enabled the richness of participants' pedagogical reasoning and practices to come to the fore and to achieve methodological triangulation. Fieldwork lasted for six months and across two school terms in 2017 and 2018. Each of the 24 teachers participated in an initial in-depth interview before their lessons were observed. The interviews followed Van Manen's (1990) concept of conversational interviewing, whereby participants were given the opportunity to seek clarification to the questions where necessary, receiving an unscripted explanation. The conversationally flexible approach enabled an authentic, flexible atmosphere where participants felt at ease to reflect on and articulate their experiences. The interview questions covered several key issues, including how the teachers planned their teaching, their methods of teaching and the reasons for using such methods. On average, in-depth interviews lasted for about fifty minutes. Of the participants, 20 consented to lesson observations. The number of lessons observed per participant ranged from one to four, depending on each teacher's availability and cooperation; 55 separate lessons were observed. Insights generated from the observations helped to further understand the interview data. In addition to the interviews and observations, there was a review of participants' lesson plans using a lesson plan review rubric. Six participants provided their written lesson plans and work scheme for review. The collection of these varied forms of data provided access to the experiential portraits of participants' reasoning and pedagogical actions.

While this study contributes to expanding the frontiers of knowledge and practice in history education more generally, it has limitations. As not all teachers participated equally in all three methods of data collection, explanations and extrapolations, as well 
as making connections between the three methods, was not always possible, and this limited, to some extent, the analysis of participants' reasoning and practice.

\section{Data analysis}

Thematic analysis was employed to analyse data, as it enhanced hermeneutic phenomenological reflection and unveiled the content and structure of participants' experiences (Van Manen, 1990). Data were transcribed and transcription errors, identifying information and redundant expressions were removed. Analysis involved multiple reading of the transcripts and coding with NVivo software. Two focus prompts were generated for the first two research questions to guide reflection on what participants were saying, doing or thinking. Statements were generated in a completethe-sentence format as follows:

Research question 1: How do history teachers reason about their pedagogy?

Focus prompt 1: In reasoning about their pedagogy, history teachers consider...

Research question 2: Do teacher practices align with constructivist principles?

Focus prompt 2: The practices teachers employ in teaching are ...

Concepts or expressions that most appropriately filled the blank spaces were used as codes to represent significant information. The focus prompts allowed for descriptive and interpretative engagement with the data and grounded the codes in the data. Connections between and among codes were looked for and clustered to create experiential categories. The codes and categories were re-examined with focus on identifying broader patterns of meaning that were evocative in the data in order to

Table 1: Descriptive overview of the categories of analysis

\begin{tabular}{|c|c|c|}
\hline & Subcategory and frequency (n) & $\begin{array}{l}\text { Total sample }(\mathrm{N}) / \\
\text { data source }\end{array}$ \\
\hline \multirow{2}{*}{$\begin{array}{l}\text { Finding 1: Adaptivist and } \\
\text { loyalist interpretations of the } \\
\text { history curriculum }\end{array}$} & Use of the history curriculum: $n=24$ & $\mathrm{~N}=24$ /interviews \\
\hline & $\begin{array}{l}\text { Interpretation of the history curriculum } \\
\text { Adaptivist: } n=16 \\
\text { Loyalist: } n=8\end{array}$ & $\mathrm{~N}=24$ /interviews \\
\hline \multirow{2}{*}{$\begin{array}{l}\text { Finding 2: Inconsistent } \\
\text { lesson planning, yet attention } \\
\text { to student background } \\
\text { knowledge }\end{array}$} & $\begin{array}{l}\text { Lesson planning: } n=6 \\
\text { Scheme of work: } n=5\end{array}$ & $\begin{array}{l}\mathrm{N}=24 / \text { lesson plan } \\
\text { and scheme of work }\end{array}$ \\
\hline & $\begin{array}{l}\text { Acknowledgement of student } \\
\text { background knowledge: } n=24\end{array}$ & $\mathrm{~N}=24$ /interviews \\
\hline \multirow[t]{4}{*}{$\begin{array}{l}\text { Finding 3: Discursive versus } \\
\text { didactic practices }\end{array}$} & $\begin{array}{l}\text { Acknowledgment of student-centred } \\
\text { approaches to teaching: } n=24\end{array}$ & $\mathrm{~N}=24$ /interviews \\
\hline & $\begin{array}{l}\text { Discursive orientation: } n=10 \\
\text { Didactic orientation: } n=14\end{array}$ & $\mathrm{~N}=24$ /interviews \\
\hline & $\begin{array}{l}\text { Discursive practice: } n=9 \\
\text { Didactic practice: } n=11\end{array}$ & $\begin{array}{l}\mathrm{N}=20 / \text { lesson } \\
\text { observations }\end{array}$ \\
\hline & $\begin{array}{l}\text { Post-lesson reflection } \\
\text { Acknowledgement of the limitations } \\
\text { of approach used: } n=14 \\
\text { Defensive of their approach: } n=8\end{array}$ & $\begin{array}{l}\mathrm{N}=18 / \text { post-lesson } \\
\text { interviews }\end{array}$ \\
\hline
\end{tabular}


arrive at themes that were significantly meaningful, internally coherent and bounded, and yet connected enough to produce a compelling account of the data. The findings present the voices of teachers along three themes, while the discussion explicates their subtleties and complexities. As much as possible, simple frequency counts (n) are used as a descriptive measure to indicate the number of participants who expressed particular beliefs or carried out specific practices in order to highlight their typicality. These frequency counts have no inferential merit beyond the participants in this paper. Table 1 shows a summary of the number of participants belonging to the different categories of analysis.

\section{Findings}

\section{Adaptivist and loyalist interpretations of the history curriculum}

All participants recognized the history curriculum as a guide that specifies the knowledge and competencies that students should attain in history and, therefore, acknowledged its importance in the selection of topics and instructional planning. (Pseudonyms have been used for participants to protect their identity.) Nelson stated: 'I plan with the syllabus. So if I know that I am covering two or three topics in a term, I break them down further for the lesson presentation or teacher-student interaction.' Overall, participants' use of the curriculum revealed two approaches to curriculum interpretation: adaptivist and loyalist. The majority of participants, who were adaptivists $(n=16)$, displayed flexibility in their use of the curriculum by reinventing it in the classroom. These participants reshuffled the topics, used recent events as springboards to teach about the past, and taught beyond the content prescriptions of the curriculum. Bernard explained how he organized topics for teaching purposes:

Per the arrangement of the syllabus, the Missionary Activities come first, before the Partition of Africa. But ... you realize that there is another topic that deals with impact of the European presence, so I do not see why I should treat the missionaries' presence first. I teach it when I am treating the impact of the European presence. I try to organize it in that manner because sometimes treating certain topics together gives a complete understanding.

This result suggests that adaptivist participants did not perceive the history curriculum as a linear set of topics to be followed, but as comprising interrelated historical issues that are not exclusive of each other. With this understanding, they linked topics that shared temporal, geographic or causal connections for the purpose of enhancing students' understanding. Kaitlan indicated: 'When talking about the development of agriculture in [ancient] Egypt, you have to talk about agriculture in Ghana, because there is a linkage. You want to establish the times that agriculture started in Egypt and in Ghana.' The adaptivist orientation was further visible in how these participants explained the prescribed content by drawing on events that were not included in the curriculum. Albert gave an example: 'On a topic like the Trans-Saharan Trade, syllabus and textbooks are mostly silent on the dominant role played by the Tuareg. I add this information, since it is important to the topic.' This interpretation of the history curriculum suggests that adaptivist participants sought an idealized version of the curriculum with a view to improving student understanding.

Conversely, loyalist participants $(n=8)$ were prescriptive in approach, as they believed that the curriculum is systematized and developmentally organized to achieve progressive improvement in student learning. Cosmos indicated: 'What I 
have observed from the syllabus is that it is based on the stages of development ... I think it is perfectly arranged.' Operating with this understanding, loyalists adhered to the contents and arrangement of the curriculum without making any adjustments or additions. Thompson maintained:

There is no topic in Form 3 that I think can fit in Form 1. If I bring a topic from Form 3, the Form 1 student may not understand it. So ... I teach according to how the curriculum designers have presented it.

This finding shows that even though loyalists recognized the idea of adapting topics, their non-adaptive method was informed by their view that swapping topics that were two or three years apart in the curriculum could hinder students' understanding and future learning. Therefore, strict adherence to curricular arrangements was necessary to ensure that they achieved the stated objectives of the history curriculum.

Lesson observations showed that despite most participants' adaptivist orientation to curriculum interpretation, only Bernard reorganized the curriculum's arrangement in class. For instance, Bernard treated the Bond of 1844 and the Anglo-Asante Wars, which were scheduled to be taught later in the curriculum, before teaching the Partition of Africa, which was placed earlier in the curriculum. While teaching the Partition of Africa, Bernard linked these topics by stating that the reasons for the Anglo-Asante Wars were economic and political, and that it had been for similar reasons that the scramble and Partition of Africa had taken place. Most adaptivist-oriented participants' reasons for not adapting the curriculum during their teaching were related to the need to meet the demands of accountability. For example, Fidelis, who expressed an adaptivist perspective, maintained that it was still necessary to complete all curriculum topics: 'I make sure [that] ... they [students] are able to complete the syllabus because of the questions that are asked in the final exams.' This result shows that despite participants' varied approaches to interpreting the history curriculum, the majority operated with a common approach to curriculum implementation by teaching the topics as presented to them.

\section{Inconsistent lesson planning, yet attention to student background knowledge}

Participants indicated that they prepared lesson plans as part of their instructional planning. Nevertheless, only six participants submitted lesson plans. Three participants explicitly refused to provide their lesson plans for the research study, while the remainder noted that they did not prepare lesson plans since they have been teaching the same topics every academic year for a long time. A review of the available lesson plans showed that there was limited attention given to student engagement, as the lesson plans of three participants focused on lesson objectives and content, with scant indications of corresponding classroom activities for the attainment of the set objectives. The other three participants planned activities such as brainstorming, group work and discussions. Yet, apart from linking topics to students' prior knowledge, they did not implement such planned activities in their lessons. For instance, two participants had planned to use group activity, but they used lectures and textbook readings during their lessons. In contrast, even though another participant did not initiate her planned brainstorming activity, she engaged students by inviting them to demonstrate the use of primary sources about traditional medicine. Another participant did not document any student-centred activity in her lesson plan, but she employed small-group presentations in her lessons.

The mismatch between what was planned and what was implemented suggests that these participants did not limit themselves to their lesson plans but were open to 
alternative approaches as the classroom situation unfolded. One participant's postlesson comments support this: 'the more you teach, the more ideas come up'. Apart from these reasons, it is also possible that these participants changed their minds and decided to do something they perceived to be more conventional because they were being observed. Findings also show that four other participants did not prepare lesson plans but incorporated group activities such as source analysis, group discussions and student presentations on assigned topics. These participants appeared to have maintained instructional flexibility due to classroom uncertainties, as Martha noted after her third lesson: 'I did not actually plan to use the method that I used but when I got to the class, it became necessary.'

Other important findings relate to consideration of student characteristics, prior knowledge and contextual arrangements in the making of instructional decisions. All participants noted that building on students' prior knowledge gave them the opportunity to address any misrepresentations in students' thinking about the past, as Boniface indicated:

Most of the stories that students come into the classroom with are orally transmitted through the communities they come from. But oral tradition could include mythology. So I let students know the mythological aspects of oral tradition ... I am able to link their prior knowledge to the things they have to study.

Further, participants demonstrated their understanding of the importance of student knowledge and skill in their lesson plan, as most of their lesson objectives were stated in terms of what students were expected to achieve at the end of each lesson. This is significant because constructivist education considers student needs and interests as pertinent to meaningful learning. However, the objectives were limited to the knowledge aspect of the curriculum's profile dimension, which runs counter to the curriculum requirement that teachers give more focus to applicable skills (Ministry of Education, 2010). Moreover, the scant use of written lesson plans among most participants limited their instructional record keeping, which could have served as a resource for improving practice.

\section{Discursive versus didactic practices}

All participants acknowledged that engaging students and offering them positive reinforcement reduces abstraction, offers them a sense of investment and personal responsibility in their learning, and enhances interest and understanding. Allan, for instance, indicated: 'You structure the teaching in a way that will not make it look abstract. You recount or tell the incident by using methods that would make it relevant so that they [students] begin to appreciate it.' To this end, they highlighted the use of a range of discursive and collaborative methods of teaching, including whole-class discussions, group activity, presentations, role play and field trips to historic sites. Barns summarized these by describing his approach to teaching: 'I am able to use various techniques like the questioning method, discussion method, demonstration, debates and others. By involving them [students] in class and giving them tasks to do, ... their analytical skills are developed.' Furthermore, participants noted that they often linked their lessons to happenings in the community to enable students to identify with the events. Gregory maintained: 'Yesterday, we were looking at traditional marriage. Students have a lot of information about this topic. So I asked the whole class what they knew about marriage and guided them to understand it better.' Reviews of lesson plans support this finding, as four participants planned teacher-student activities such 
as class discussions and group presentations that aimed for student involvement and scaffolding of learning.

A participatory, facilitative approach to history teaching aligns with constructivist theory. Nevertheless, despite the acknowledgement of such student-centred teaching methods, most participants ( $n=14)$ admitted that they often used didactic or narrative approaches for their lessons. These participants' reasons for choosing didactic methods were twofold. First, some participants $(n=6)$ noted that they used the approach for topics that were abstract. Tony, for instance said: 'it is mainly because the topic itself is factual, and students have little or no idea about it'. For the other eight participants, didactic (teacher-directed) methods were their usual approach to teaching, even though they recognized the limitations of the approach. Yawson explained:

Most of the time ... I go and give them the facts. But that may not be good for the students because ... they may not understand what I have actually taught them. So, that is not helping but ... I need to complete a syllabus.

This response suggests that the pressure to complete the curriculum compelled most participants to feel that they had to use a didactic approach.

A comparative analysis of lesson plans and classroom implementation reflects this orientation towards didacticism. For instance, even though one participant planned teacher-student activities such as class discussions and group activity, she narrowed herself to textbook explanations. Observation of classroom lessons revealed that out of the 20 participants observed, a majority $(n=11)$ adopted the didactic approach, as they focused on textbook reading interspersed with teacher explanations while students listened, took down notes and responded to a few recall questions. Classroom exploration of multi-perspectivity was limited, as only three participants presented varied perspectives on events, while the remaining participants focused on single, grand narratives without providing opportunities for student interpretation. Likewise, only two participants used primary and secondary sources in their lessons. For the remaining participants $(n=9)$, there were a few cases of interactive approaches such as whole-class discussions and group presentations, but these approaches were in the main dominated by content. For example, one participant initially involved students in class discussions, but as the lesson progressed, he began to dominate it with teacher talk. Conversely, another participant used group activity, tasked students to analyse secondary sources on four Anglo-Asante Wars, and provided guidance and support. This participant noted after the lesson that his rationale for using the approach was to foster cooperation and facilitate thinking: 'I aimed at ensuring that this would build them for teamwork, it will build the students to do analytical reasoning and questioning.'

The results generally show that participants' classroom practices were largely content-driven, as activities and methods for engaging students and equipping them with disciplinary skills did not feature prominently among most participants. Content coverage also formed a major part of participants' lesson plans and work schemes. The available schemes of work showed a list of topics for each week and the associated textbook references, with no indications of the teacher-student activities that were to accompany such topics. Likewise, only four out of the six participants who prepared lesson plans included classroom activities such as small-group presentations. Yet, in all six cases, content attracted the most attention. In a post-lesson interview, Tony justified his focus on content and the use of reading methods: 'When I ask them [students] to read, they remember it more because they heard a colleague reading it.' Out of the 18 teachers who participated in post-lesson interviews, most $(n=14)$ acknowledged 
that alternative approaches could have enhanced their teaching. For instance, Jake indicated: 'Next time, I will vary my teaching methods. I will group students to research ... and we will compare their findings.' The fact that these participants admitted the restrictions of their methods suggests that they were aware of the limitations of such methods, but that they used them regardless, perhaps, in order to facilitate coverage of the curriculum. Notwithstanding this, four participants who employed didactic methods were insistent that they achieved student engagement. For instance, Albert was defensive: 'What I used was a discussion method and I consider it appropriate for the lesson.' The instances of inconsistency between post-instructional reflection and classroom reality point to contradictions in these participants' thinking about their pedagogy, since they appeared to misinterpret their own practices.

\section{Discussion}

Planning, teaching and reflection on teaching are inextricably interconnected and essential for professional practice evaluation for improvement. Participants' pedagogical reasoning highlighted their recognition of the importance of planning in determining what students can achieve in history. Their use of the curriculum as a planning guide for instructional purposes was not unexpected, as teachers' practices have been noted to be influenced by curriculum standards that are often determined by state or central governments (Grant, 2003). The adaptive interpretation of the curriculum is representative of an explanatory theory that is suited to Burston's (1954) topic method approach to teaching history. Loyalist participants who adopted an exclusivist approach to topics orient towards a uniqueness approach to history by which events are treated without connecting them to other events or topics (Evans, 1994). Even though this study did not investigate the practical benefits of any approach to curriculum use, adaptivist participants indicated that the approach helped to achieve student understanding. Therefore, it can be argued that adapting the curriculum makes it possible to contextualize teaching and learning by considering prevailing instructional variables. Kingsford, for instance, stated: 'The syllabus may recommend that some topics come first, but per the level of the students, it may be necessary to bring it second or third.'

This finding highlights the situatedness of teaching. That is, even though teachers are expected to implement the curriculum as designed, these participating teachers felt empowered to modify the curriculum to suit their classroom conditions and students' needs. However, the limited attempts in the classroom at curriculum modification show that even though perspectives on the approach to curriculum interpretation and use differed among participants, the majority of them taught the curriculum topics as designed and were, consequently, conformist in practice. Their conformist approach to the curriculum was further limited as most of them did not implement the recommended constructivist practices. This could be connected to the highly structured nature of school education in Ghana, and to the possible fear of not meeting accountability and high-stakes examination requirements. Teaching that is closely aligned to the prescripts of the curriculum topics is indicative of participants' sense of accountability to educational stakeholders for curriculum delivery, an approach that Barton and Levstik (2004) observe as being common in history education.

Even though participants mentioned that they prepared lesson plans, it was surprising that not all of them undertook written lesson planning, as teachers in Ghana are professionally required to have written lesson plans for every lesson they teach. This raises concerns about participants' commitment to this important professional 
requirement for teaching in Ghana. The absence of written lesson plans by most participants perhaps suggests that since participants were experienced history teachers (with an average of six years of teaching experience) they operated using a tacit form of understanding of what was needed in their teaching as a result of theoretical and practical expertise acquired from years of practice. For example, some participants noted that they did not prepare lesson plans because they had been teaching the same content for several years. This revelation aligns with the observation that as teachers gain expertise, they draw practical knowledge from their experience and work with mental forms of planning (Farrell, 2002). Research also shows that teachers did not worry about planning lessons because the actual classroom teaching tended to diverge from their planned lessons (Farrell, 2013). The few cases where participants implemented unplanned activities support the finding that teachers drew from experience and tacit knowledge, indicating that unplanned pedagogy could become useful in the classroom. The few participants who prepared lesson plans and schemes of work did not implement their plans in the classroom. This indicates that the few cases of lesson planning were aimed at addressing school and professional demands rather than improving classroom practice. Rene, for instance, confessed during the in-depth interview: 'It is just for formality sake. They come and inspect it.' Perhaps the strict requirements for lesson planning compelled these participants to present something for the records. This is similar to the finding that strict requirements for planning led to teachers falsifying their lesson plans in order to satisfy the demands of education administrators (Shaw, 2017). Incomplete, inconsistent and inaccurate planning decisions and record keeping mean that the conduct and progress of history teaching are not accurately represented to school authorities and supervisory bodies. The result is a lack of alignment between educational innovation and classroom reality - since information about practice often informs policy priorities and decisions made by teachers, school administrators and curriculum planners.

Participants acknowledged students' existing world views of history, and recognized that participatory methods such as group discussions, class presentations, source analysis and visits to historic sites are desirable in history teaching, yet only a few utilized such methods in their teaching. Perhaps the few participants who used participatory approaches drew from the curriculum, which recommends the use of such constructivist methods. However, the generally content-focused nature of lessons among participants contradicted their interview responses that they frequently employed a variety of student-centred, enquiry-based teaching strategies. Some participants indicated support for using narrative methods to introduce unfamiliar topics. Yet, given that most of the topics taught by participants during the lesson observations concerned issues to which students could relate - such as the traditional economy, social and political organization, social developments and independence issues - the use of narrative approaches undermines such an explanation. Despite the argument that acquisition of substantive knowledge is fundamental to domain-specific conceptual understanding, and should therefore be introduced first before procedural concepts (Lee, 2011), participants' emphasis on content, with little focus on associated activities and skills, hinders the attainment of discipline-specific dispositions. Even though elements of constructivism existed so far as taking into account students' experiences was concerned, there was a lack of clear, consistent adoption of a disciplinary structure or constructivist orientation in the way participants planned and carried out their teaching of history. Perhaps, through their narrative approach to history, participants sought to teach the best stories as grand narratives to enhance the collective memory, as some researchers have observed (Ahonen, 2017). 
The foregoing discussion reveals that participants' perception of history teaching differed significantly from their actual approach to teaching the subject. Factors accounting for this gap - aside from the role of experience and tacit knowledge, which have already been discussed - are mainly related to limited logistical provisions, the overcrowded nature of the history curriculum, and accountability requirements. In terms of logistical provisions, there were not sufficient resources for the teaching of history. Paucity of resources such as internet, maps, charts, computers and overhead projectors in the participating schools suggests lack of access to materials of historical and pedagogical utility to support teaching. The majority of participants indicated their willingness to use such resources, if they were available. For instance, Rene said she could use her personal projector, if there was electricity connection in the classroom: 'If we had access to electricity in the classroom, I could bring some projectors to class.' It is therefore highly likely that the absence of these teaching resources informed the widely used didactic approach to the teaching of history. As Albert noted: 'I am not happy to be using the lecture method all the time. There are many things we need in order to teach well.'

The overcrowded nature of the history curriculum and formal accountability requirements provide further explanation for the reasoning-practice gap. There were indications that the curriculum was overloaded with topics (the history curriculum outlines 22 units to be completed within a three-year period), which compelled teachers to seek quick curriculum coverage through didactic methods, rather than implementing activities that could enhance enquiry and understanding. The detail expected from these units made constructivist teaching of these topics within the allotted period problematic for participants. Evidence from the in-depth interviews attests to this difficulty; Jake, for example, stated: 'I do not think any history teacher can complete the syllabus within three years. I am often compelled to talk to students, sometimes using the lecture method.' This finding suggests that unlike traditional methods, constructivist pedagogy is time-consuming and does not facilitate quick curriculum coverage. Further, because there were high expectations regarding teacher accountability, measured by high student achievement, the most straightforward way around this dilemma for participants was to attend to content coverage. Boniface indicated: 'If they [students] acquire only the skills in history and they do not finish the syllabus, and hence, they are not able to pass well, ... l, the teacher, will be questioned.' Other factors could also contribute to the disparity between teacher reasoning and classroom practice; the possible explanations provided by other variables in analysing the approach taken to history teaching by participants could be the object of a further research undertaking.

\section{Results-based refinement of the reasoning-practice relationship}

Based on the sources and forms of teacher knowledge, it was hypothesized that teachers' reasoning about their pedagogy may influence how they implement their classroom practices (see Figure 1). The study found a lack of consonance between pedagogical reasoning and classroom practices. Despite the different interpretations of the curriculum, most participants were loyalist in implementing the curriculum topics, even though their teaching approaches deviated from the constructivist recommendations of the curriculum. Indications of the importance of lesson planning, and recognition of the applicability of active, participatory teaching methods to history, reflected constructivist theory, but were found not to be widely used. Evidence from 


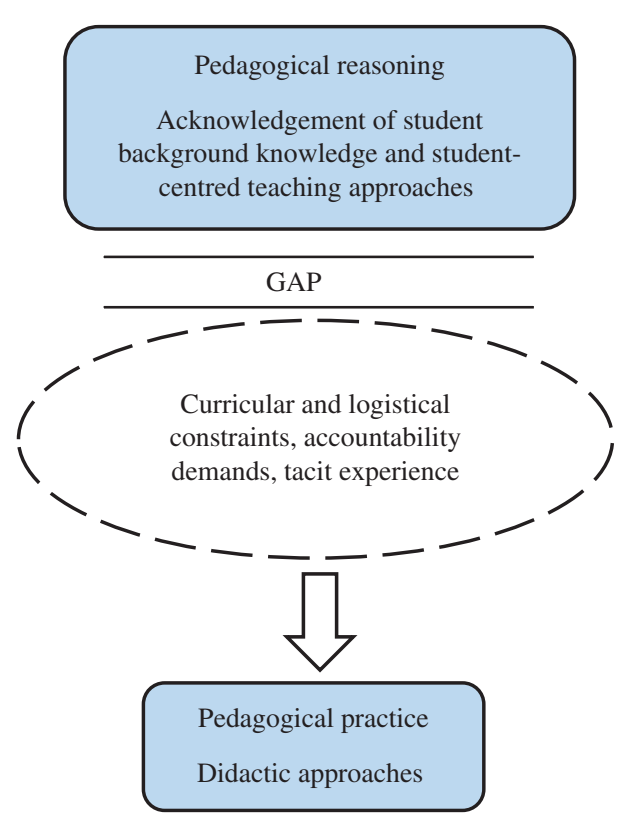

Figure 2: Revised relationship between teacher reasoning and practice

this study suggests that the teachers' reliance on experience and tacit knowledge, the need to cover a vast curriculum in a limited time, and the pressure to achieve high student performance in high-stakes examinations were key to this discrepancy. Following the findings of this study, an adjustment to the initial construct is presented in Figure 2.

Generally, the results of this study do not support earlier findings that teacher conceptions influence their approach to teaching (Bennett, 2014; Wineburg and Wilson, 1991). The revised construct therefore redefines the relationship between teacher reasoning and practice.

\section{Conclusion}

This study has explored Ghanaian history teachers' reasoning about their pedagogy, their teaching practices and whether they were consistent with constructivist principles, and the relationship between their reasoning and practice. Findings demonstrate that theory and rhetoric do not always translate into actual practice in classrooms. The classroom community of enquiry is built around the dynamics of knowledge of students, and knowledge of the subject and its pedagogical applications and representations (Shulman, 1987). Teachers' possession of this body of knowledge is the necessary prerequisite for meaningful classroom experiences for students in history. Participants demonstrated an understanding of constructivist history pedagogy. However, the generally didactic approach to classroom practice implies that they could not transform such understandings into meaningful structures for students' understanding, as a result of constraints imposed by curricular and accountability demands, resource limitations, and tacit knowledge and experience. In effect, the enduring understanding that results from the empowerment of students to construct meaning for themselves could become elusive. Teachers' pedagogical content knowledge (Shulman, 1987) is therefore an important area to develop, since it could determine how they mediate the curriculum, approach their teaching and influence students' understanding. Further, addressing the factors that account for the gap between teacher reasoning 
and practice is essential to improving history teaching in Ghanaian schools. For history teaching in Ghana to achieve meaningful ends for students, teachers need workable systems, favourable conditions, and a clear educational direction to be developed and operationalized at the national policy level, as well as at the school and classroom level.

\section{Notes on the contributors}

Gideon Boadu recently completed his doctoral studies in education at the University of Newcastle, Australia. Dr Boadu's research applies constructivist epistemology to teaching, dwelling particularly on the nexus between teacher understandings, classroom practice, professional development and curriculum specifications. Gideon is currently a research assistant in the School of Education at the University of Newcastle.

Debra Donnelly is a senior lecturer in history education in the School of Education at the University of Newcastle, Australia. Dr Donnelly's research interests centre on the role of the visual and media in the development of historical consciousness in an age of ever-increasing access through modern technology. She is a founding member of the HERMES (Historical Experience, Representation, Media, Education and Society) research group and an editor of its journal, Historical Encounters.

Heather Sharp is an associate professor in the Faculty of Education and Arts at the University of Newcastle, Australia. Her research investigates historical representations, particularly about topics of significance to a nation's history. Heather is a founding member of the HERMES research group. She is convener of the History Network for Teachers and Researchers (HNTR) and the special issues editor of the journal Historical Encounters. Heather is currently a recipient of a Swedish Research Council grant with Ammert, Edling and Löfström that investigates the intersections of historical consciousness and moral consciousness.

\section{References}

Ahonen, S. (2017) 'The lure of grand narratives: A dilemma for history teachers'. In Elmersjö, H.A., Clark, A. and Vinterek, M. (eds) International Perspectives on Teaching Rival Histories: Pedagogical responses to contested narratives and the history wars. London: Palgrave Macmillan, 41-62.

Barton, K.C. and Levstik, L.S. (2004) Teaching History for the Common Good. Mahwah, NJ: Lawrence Erlbaum.

Bennett, S.M. (2014) 'Teachers' beliefs and implementation of historical literacy pedagogy in three advanced placement United States history classrooms'. The Georgia Social Studies Journal, 4 (2), 53-67.

Boadu, G. (2020) '"Hard" facts or "soft" opinion? History teachers' reasoning about historical objectivity'. Journal of International Social Studies, 10 (1), 161-86. Online. www.iajiss.org/index. php/iajiss/article/view/449 (accessed 14 July 2020).

Burston, W.H. (1954) 'Explanation in history and the teaching of history'. British Journal of Educational Studies, 2 (2), 112-21. Online. https://doi.org/10.1080/00071005.1954.9972915

Byrom, J. and Riley, M. (2003) 'Professional wrestling in the history department: A case study in planning the teaching of the British Empire at Key Stage 3'. Teaching History, 112, 6-14.

Evans, R.W. (1994) 'Educational ideologies and the teaching of history'. In Leinhardt, G., Beck, I.L. and Stainton, C. (eds) Teaching and Learning in History. Mahwah, NJ: Lawrence Erlbaum, 171-207.

Farrell, T.S.C. (2002) 'Lesson planning'. In Richards, J.C. and Renandya, W.A. (eds) Methodology in Language Teaching: An anthology of current practice. Cambridge: Cambridge University Press, 30-9.

Farrell, T.S.C. (2013) 'Reflecting on ESL teacher expertise: A case study'. System, 41 (4), 1070-82. Online. https://doi.org/10.1016/j.system.2013.10.014 
Fosnot, C.T. (1996) Constructivism: A psychological theory of learning. New York: Teachers College Press.

Gadamer, H.-G. (2004) Truth and Method. 2nd ed. London: Continuum.

Grant, S.G. (2003) History Lessons: Teaching, learning, and testing in US high school classrooms. Mahwah, NJ: Lawrence Erlbaum.

Heuer, C., Resch, M. and Seidenfuß, M. (2017) "“What do I have to know to teach history well?" Knowledge and expertise in history teaching - a proposal'. Yesterday and Today, 18, $27-41$. Online. https://doi.org/10.17159/2223-0386/2017/n18a2

Husbands, C., Kitson, A. and Pendry, A. (2003) Understanding History Teaching: Teaching and learning about the past in secondary schools. Milton Keynes: Open University Press.

Knupfer, P. (2013) 'Consultants in the classroom: Student/teacher collaborations in community history'. The Journal of American History, 99 (4), 1161-75. Online. www.jstor.org/stable/44307509 (accessed 27 August 2020).

Lee, P. (2011) 'History education and historical literacy'. In Davis, I. (ed.) Debates in History Teaching. London: Routledge, 63-83.

Ministry of Education (2010) Teaching Syllabus for History. Accra: Curriculum Research and Development Division.

Perrotta, K. (2018) 'Pedagogical conditions that promote historical empathy with "The Elizabeth Jennings Project"'. Social Studies Research and Practice, 13 (2), 129-46. Online. https://doi.org/10.1108/SSRP-11-2017-0064

Power, S., Rhys, M., Taylor, C. and Waldron, S. (2019) 'How child-centred education favours some learners more than others'. Review of Education, 7 (3), 570-92. Online. https://doi.org/10.1002/ rev3.3137

Sharan, S. (1990) Cooperative learning: Theory and research. New York: Praeger.

Shaw, R.D. (2017) 'I can hardly wait to see what I am going to do today: Lesson planning perspectives of experienced band teachers'. Contributions to Music Education, 42, 129-52. Online. www.jstor.org/stable/26367440 (accessed 27 August 2020).

Shulman, L.S. (1987) 'Knowledge and teaching: Foundations of the new reform'. Harvard Educational Review, 57 (1), 1-22. Online. https://doi.org/10.17763/haer.57.1.j463w79r56455411

Van Boxtel, C. and Van Drie, J. (2009) 'Enhancing historical reasoning: A key topic in Dutch history education'. International Journal of Historical Learning, Teaching and Research, 8 (2), 140-53. Online. https://hdl.handle.net/11245/1.318653 (accessed 14 July 2020).

Van Manen, M. (1990) Researching Lived Experience: Human science for an action sensitive pedagogy. Albany, NY: The State University of New York Press.

Wineburg, S.S. (2001) Historical Thinking and Other Unnatural Acts: Charting the future of teaching the past. Philadelphia: Temple University Press.

Wineburg, S.S. and Wilson, S.M. (1991) 'Models of wisdom in the teaching of history'. The History Teacher, 24 (4), 395-412. Online. www.jstor.org/stable/494699 (accessed 27 August 2020). 